\title{
Litterfall, litter decomposition, soil macrofauna, and nutrient content in rubber monoculture and rubber- based agroforestry plantations
}

\author{
Uraiwan Tongkaemkaew ${ }^{1 *}$, J. Sukkul ${ }^{1}$, Narathorn Sumkhan ${ }^{1}$, Phantip Panklang ${ }^{2}$, Alain Brauman ${ }^{3}$, and \\ Roslan Ismail ${ }^{4}$ \\ ${ }^{1}$ Faculty of Technology and Community Development, Thaksin University, Phatthalung Campus, 93120 \\ Thailand \\ 2 Faculty of Natural resources, Songklanakarin University, Hatyai Campus, 90112, Thailand \\ 3 Representative of Institut de recherche pour le développement (IRD), French \\ 4 Faculty of Agriculture, Universiti Putra Malaysia, 43400, Malaysia
}

*Corresponding author: t_uraiwan@hotmail.com, uraiwan@tsu.ac.th; Tel.: +66-081-965-5583

\begin{abstract}
This study is a comparison of the litterfall, litter decomposition, soil macrofauna, and nutrient contents in rubber monoculture and rubber-based agroforestry plantations. The three intra-couple differences examined are rubber with pakliang (RP) compared with rubber monoculture (RMP), rubber with timber (RT) compared with rubber monoculture (RMT) and rubber with fruit (RF) compared with rubber monoculture (RMF). Rubber plantation systems were selected at 3 plantations located in nearest pairs at 18 plantations in total. Data collected included litterfall at monthly intervals from October 2016 to April 2017, as well as decomposition conditions for assessment at the end of the experimental trials. Soil samples examined the species and number of macrofaunal and decomposition measurements of mesofauna by using Lamina bait scale to analyze nutrient content. Results showed the litterfall of leaves, twinges, and fruits in rubber monoculture and rubber-based agroforestry plantations were not significant between pair comparisons. This showed leaves fell at a high incidence. However, RT experienced a higher trend in litterfall. Decomposing litterfall was also not significant between pair comparisons, but when compared by associated plant species found that RT trends were more likely to experience higher decomposition rates and the litter index was higher as well. Macrofauna in the topsoil $(0-5 \mathrm{~cm})$ and subsoil $(5-10 \mathrm{~cm})$ were not significant. The composition of mesofauna was found at high decomposition rates in RF, RP, and RT. Organic matter and nutrient contents were not significant in both soil layers. Our data emphasizes that rubber-based agroforestry plantations help regulate $\mathrm{C}$ and nutrient cycles, implying that external input fertilizer management requirements for rubber farmers decreased.
\end{abstract}

Keywords: litter index; mesofauna; nutrient content; organic matter; associated plant species

\section{Introduction}

Rubber (Hevea brasiliensis) first expanded cultivation in southern Thailand in 1899 by using natural plant species called jungle rubber plantations. In 1960, the Office of Rubber Replanting Aid Fund or ORRAF (now The Rubber Authority of Thailand: RAOT) promoted plantation rubber by using hybrid varieties instead of jungle rubber. This resulted in rubber monoculture expanding to other regions, especially in the northeastern region (ORRAF, 2006). This helped farmers to claim funds for rubber cultivation and integrating with other commercial tree crops as recommended by government agencies to maximize land use. Nevertheless, rubber agroforestry practices among farmers are not currently widespread. This may be due farmers lack of knowledge in managing land plots that include rubber, especially in relation to litterfall and litter decomposition effects to soil fertility and soil macrofauna.

Yang, et al. (2004) reported that litterfall and litter decomposition is a source of essential nutrients such as $\mathrm{N}, \mathrm{P}$, and $\mathrm{K}$ returned to plants. There were also incidence of $\mathrm{Ca}$ and $\mathrm{Mg}$, depending 
on the species and the type of litterfall. Wang, et al (2008) found that litter production, leaf litter decomposition and nutrient returns (e.g. mean annual litter production) was significantly higher in mixed stands than monoculture ones. The returns of $\mathrm{N}, \mathrm{P}$ and $\mathrm{K}$ via leaf litter were significantly higher in the mixed stands than pure stands, but the returns of $\mathrm{C}, \mathrm{Ca}$ and $\mathrm{Mg}$ between both stands did not differ significantly. The introduction of the broadleaved tree into monoculture stands helped to increase litter production and nutrient returns, thus providing advantages in degraded soil conditions helping with sustainable land management. Chen, et al. 12017) found that rubber-based agroforestry treatments as $H$. brasiliensis-C.arabica, $H$. brasiliensis-T. cacao, $H$. brasiliensis-F. macrophylla and $H$. brasiliensis $-D$. cochinchinensis had significantly increased total soil organic carbon (SOC) and $\mathrm{N}$ contents, and furthermore enhanced the formation of macroaggregates compared to the rubber monoculture treatment. The soil surface cover with constant leaf litterfall and extensive root systems in the rubber agroforestry systems increased organic carbon and nitrogen in the soil, helping to improve soil aggregation, reducing soil erosion, decreasing carbon and nitrogen loss, and ultimately improving carbon and nitrogen accumulation rates.

In the plots of plants with a wide range of plant species, the amount of litterfall and the quantity of macrofauna in the soil increased nutrient returns in the soil. Therefore, the diversity of macrofauna in the soil is indicative of the richness of the ecosystem. This is especially evident in monoculture areas, where litter fall is significantly less, affecting species and quantity of macrofauna (Pabsta, et al., 2013). Macrofauna is the most important priority for decomposition, which works by eating residual plants and animal that release waste in the form of organic matter. This organic material gets incorporated into the soil. The organic matter is then decomposed by microorganisms and eventually becomes organic carbon compounds that help to improve soil structure and provide nutrients to plants (Austin, et al. 2014). Soil fauna important in soil includes termites, ants, nematodes. Their activities help move the soil from the upper layer to the lower layer or the lower layer to the upper layer. This incurs gaps in the soil, which then allows water and air to penetrate. The activity of these organisms influences soil processes that control the availability of plant nutrients such as nitrogen, and affects organic matter dynamics (Sarah, 2016). At the study sites, rubber-based agroforestry systems are considered the best way to improve soil properties.

In this study, we investigated litterfall, litter decomposition, soil macrofauna and nutrient content in rubber monoculture and rubber-based agroforestry systems in order to make a comparison. This is useful information for rubber farmers in the management of rubber farms and helps as a decision support tool for farmers who decide to grow rubber-based agroforestry systems.

\section{Materials and Methods}

\subsection{Site study and plot pair trials}

The study area was conducted through a purposive selection in Srinakarin and Si Banphot Districts, Phatthalung Province, Southern Thailand, whereby planting systems are conducted as both monoculture and single crop systems of rubber cultivation. We chose intra-couple differences models of rubber-based agroforestry systems, in which each of them were compared with the closest monoculture rubber plots at the same age (from 10 to 30 years old). These plot pairs include the following:

(1) Rubber monoculture (RM) + Rubber with Fruit trees (RMF) (Pair I);

(2) Rubber monoculture (RM) + Rubber with pakliang (RMP) (Pair II); and,

(3) Rubber monoculture + Rubber monoculture with Timber trees (RMT) (Pair III). In three intra-couple differences, we investigated 3 replications (Figure 1 ).

Therefore, we investigated 3 cases* 2 systems* 3 replicates for a total of 18 distinct plots. Our choice in rubber plantations was based on a previous socio-economic study conducted by Stroesser et al. (2018). They found that Phatthalung province had the best agroforestry systems, both in terms 
of land and labor valorization, associated rubber trees with fruit and timber trees. Farmers also take on off-farm activities to complement their family income. We selected the 2 districts as representative due to around $50 \%$ of rubber-based agroforestry systems located in the study area. For terms and abbreviations, we used many abbreviations in this article including P: Pakliang (Gnetum gnemon), F: Fruit trees (Mangosteen: Garcinia mangostana), T: Timber trees (Hopea odorata) and RM: rubber monoculture (clone RRIM 600). The study was conducted from October 2016 to April 2017.
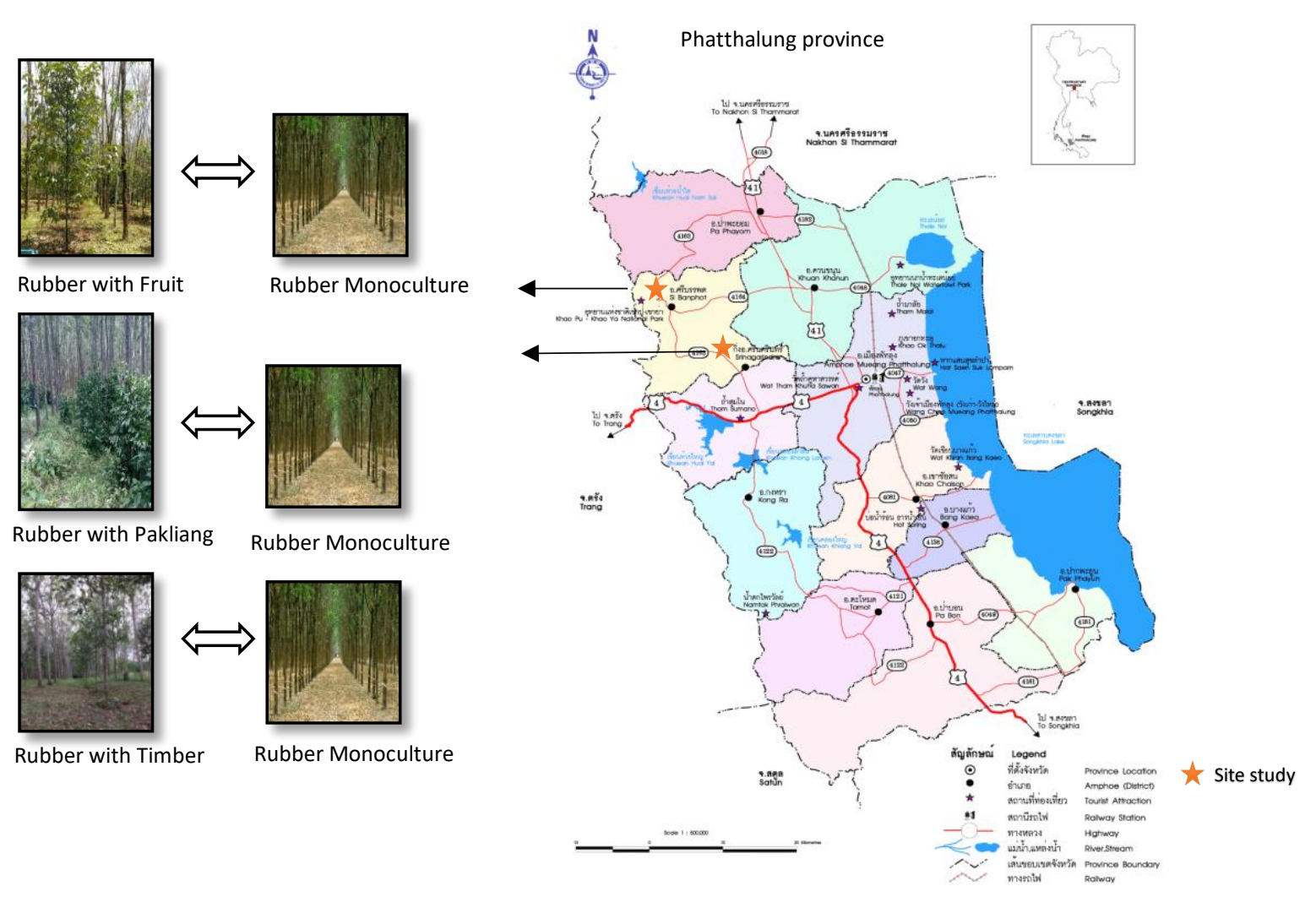

Figure 1. Site study and plot pair trials

\subsection{Data collection and analysis}

\subsubsection{Litterfall}

The selected locations of litterfall samples were collected at three points (replications) at the head, the middle, and the end of the plot trials by diagonal collection methods. The litter tray size sought to obtain litterfall samples harvested over a $10 \times 10 \mathrm{~cm}^{2}$ square plot area. Additional specifications included collections at $100 \mathrm{~cm}$ height from the ground by placing 2 litter trays in between the rubber rows and between rubber trees ( 1 point). Monthly litterfall samples were collected and dried over a period of 48 hours at $65^{\circ} \mathrm{C}$ and weighed. Thereafter, litter elements were separated, such as the leaves, twigs, and fruits to determine the dry weight of the various parts. Data obtained were analyzed for ANOVA on the intra-couple difference at $95 \%$.

\subsubsection{Litter decomposition:}

Square clear plastic sheets of $20 \times 20 \mathrm{~cm}^{2}$ were placed at three points in the plot trials by the diagonal method, in which all the humus samples were collected from under the plastic sheet every month. Humus samples were collected and dried over a 48 -hour period at $65^{\circ} \mathrm{C}$. The entire skeleton, 
fragment, compact, fresh, cast, and wood were then weighed. Data obtained were calculated for the litter index and analyzed for ANOVA on the intra-couple difference at $95 \%$.

\subsubsection{Soil macrofauna}

Three points in the plot trials were placed by the diagonal method between rubber rows that were marked by $25 \times 25 \mathrm{~cm}^{2}$ plots at a depth of $10 \mathrm{~cm}$ to identify soil macrofauna. Macrofauna was fixed in alcohol at $70 \%$, then carried out to classification ordering at the laboratory under stereo microscope and specimen weight. The data obtained were analyzed for ANOVA on the intra-couple difference at $95 \%$.

\subsubsection{Decomposition of mesofauna}

Lamina baits were used as an indicator directly associated with the feeding activity of soil invertebrates to provide an indicator of the activity and density of soil invertebrates. The method was to dry rubber litterfall over a 24 hour period at $80^{\circ} \mathrm{C}$ and mashed into powder. Mixtures of 7.5 $\mathrm{g}$ litter powder, $17.5 \mathrm{~g}$ of cellulose, and $50 \mathrm{ml}$ of water were added then heated to $100^{\circ} \mathrm{C}$, allowed to cool, and then poured into empty holes of strips. Eight strips per point were inserted vertically to a depth of $10 \mathrm{~cm}$ along the border of the $25 \times 25 \mathrm{~cm}^{2}$, for 1 month. The empty holes, partially degraded holes, and full holes were scored respectively by a 0,1 and 2. The data obtained were analyzed for ANOVA on the intra-couple difference at $95 \%$.

\subsubsection{Physical-chemical soil properties}

We collected soil from 2 layers at 0 to $5 \mathrm{~cm}$ and at 5 to $10 \mathrm{~cm}$ in three points in the plot trials by diagonal method between rubber rows. The dried soil was then taken to the Land Development Department laboratory for analysis of PH, EC, Organic matter, Phosphorus, Potassium, Calcium, and Magnesium content. The data obtained were analyzed for ANOVA on the intra-couple difference at $95 \%$.

\section{Results and Discussion}

\subsection{Litterfall}

Litterfall in the three intra-couple differences found leaves, twigs, and fruits not statistically different from one another. However, the leaves and twigs were at high falling levels in pair II (RP and RMP) and pair III (RT and RMT), compared with the pair I (RF and RMF). Fruit deposited at the highest levels in pair I (RF and RMF), particularly in RF plots (Table 1). The average litterfall in rubberbased agroforestry systems were found in stand trees (RF and RT), which were higher than shrub trees (RP). Rubber monoculture (RM) still experienced high litterfall when compared with pakliang (RP) (Figure 1). Normally, litterfall in the forest areas of Phatthalung province is high from January to March because this is the period that the dry season affects trees in Southern Thailand. In these trials, RT had a tendency to have an increased fall of humus in the dry season, especially leaves, branches, and fruits respectively. Kaspari et al. (2008) reported that $90 \%$ of litter falling as leaves and twigs failed to increase with fertilization, but reproductive litter (fruits and flowers) resulted in increases of $43 \%$ with $\mathrm{N}$. K enhanced cellulose decomposition. One or more micronutrients enhanced leaf-litter decomposition. P enhanced both. Apart from litterfall, Cizungu et al. (2014) reported that forests and mono-eucalypts had high fall of leaves followed by fruit and bark. However, this study focused on RT high falling rate of litterfall, but this does not necessarily mean the soil was higher in nutrients as well. It depended on the ability of the degradation of the humus in that area related to other physical, biological and chemical factors. 
Table 1. Litterfall ( $\mathrm{kg} / \mathrm{ha}$ ) in rubber monoculture and rubber-based agroforestry systems.

\begin{tabular}{|c|c|c|c|c|c|c|c|c|c|}
\hline \multirow{2}{*}{ Litterfall } & \multicolumn{3}{|c|}{ Pair I } & \multicolumn{3}{|c|}{ Pair II } & \multicolumn{3}{|c|}{ Pair III } \\
\hline & $\mathrm{RF}$ & RMF & T-test & RP & RMP & T-test & RT & RMT & T-test \\
\hline Leaves & 8.78 & 8.34 & ns & 11.26 & 10.06 & ns & 11.26 & 10.06 & ns \\
\hline Twigs & 1.98 & 1.92 & ns & 2.17 & 2.16 & ns & 2.17 & 2.16 & ns \\
\hline Fruits & 0.93 & 0.23 & ns & 0.19 & 0.20 & ns & 0.19 & 0.20 & ns \\
\hline Mean & 3.90 & 3.49 & & 4.54 & 4.14 & & 4.54 & 4.14 & \\
\hline
\end{tabular}

Note: ns=not significant, RF=rubber with fruit, RMF=rubber monoculture compared with $\mathrm{RF}, \mathrm{RP}=$ rubber with pakliang, $\mathrm{RMP}=$ rubber monoculture compared with $\mathrm{RP}, \mathrm{RT}=$ rubber with timber and $\mathrm{RMT}=$ =rubber monoculture compared with RT.

\subsection{Litter decomposition}

The litter index (entire, skeleton, fragment, compact, fresh, cast and wood) of the three intracouple differences were not significant. On its entirety, the skeleton and fragment in the three pairs had less decomposition. RT and RMT in pair III had the residual highest results when compared in the pair I and pair II trials (Table 2). Comparing the average of litterfall and litter index found that RT had high levels both in fall and remains of plant parts from degradation. RP found less fall and high remains of plant parts from degradation. RM and RF had high falling and fewer remains of plant parts from degradation (Figure 2). This study is also consistent with Pausch et al. (2013) and Cizungu et al. (2014), which reported that plots with mixed-species were highly residual and it was found to have high degradation as well. Soil organic $\mathrm{N}$ in rubber-based agroforestry plots may be more significant than rubber monoculture plots. The litterfall of rubber-based agroforestry shows that carbon return system is higher than monoculture rubber. Constituent organic compounds and major elements involved in the fixation of energy by photosynthesis influences the carbon cycle and provides a valid means of examining similarities in ecosystem function.

Table 2. Litter index ( $\mathrm{kg} / \mathrm{ha}$ ) in rubber monoculture and rubber-based agroforestry systems.

\begin{tabular}{|c|c|c|c|c|c|c|c|c|c|}
\hline \multirow{2}{*}{ Litter index } & \multicolumn{3}{|c|}{ Pair I } & \multicolumn{3}{|c|}{ Pair II } & \multicolumn{3}{|c|}{ Pair III } \\
\hline & $\mathrm{RF}$ & RMF & T-test & $\mathrm{RP}$ & RMP & T-test & RT & RMT & T-test \\
\hline Entire & 0.64 & 0.60 & ns & 0.63 & 0.76 & ns & 0.82 & 0.64 & ns \\
\hline Skeleton & 0.17 & 0.20 & ns & 0.32 & 0.30 & ns & 0.30 & 0.18 & ns \\
\hline Fragment & 0.46 & 0.49 & ns & 0.46 & 0.64 & ns & 0.72 & 0.52 & ns \\
\hline Compact & 0.00 & 0.00 & ns & 0.04 & 0.01 & ns & 0.10 & 0.04 & ns \\
\hline Fresh & 0.48 & 0.48 & ns & 0.75 & 0.53 & ns & 0.77 & 0.51 & ns \\
\hline Cast & 0.40 & 0.22 & ns & 0.49 & 0.37 & ns & 0.55 & 0.34 & ns \\
\hline Wood & 0.57 & 0.20 & ns & 0.80 & 0.32 & ns & 0.71 & 0.42 & ns \\
\hline Mean & 0.39 & 0.31 & & 0.50 & 0.42 & & 0.57 & 0.38 & \\
\hline
\end{tabular}

Note: $n s=$ not significant, RF=rubber with fruit, RMF=rubber monoculture compared with RF, RP =rubber with pakliang, RMP=rubber monoculture compared with $\mathrm{RP}, \mathrm{RT}=$ rubber with timber and $\mathrm{RMT}=$ rubber monoculture compared with RT. 


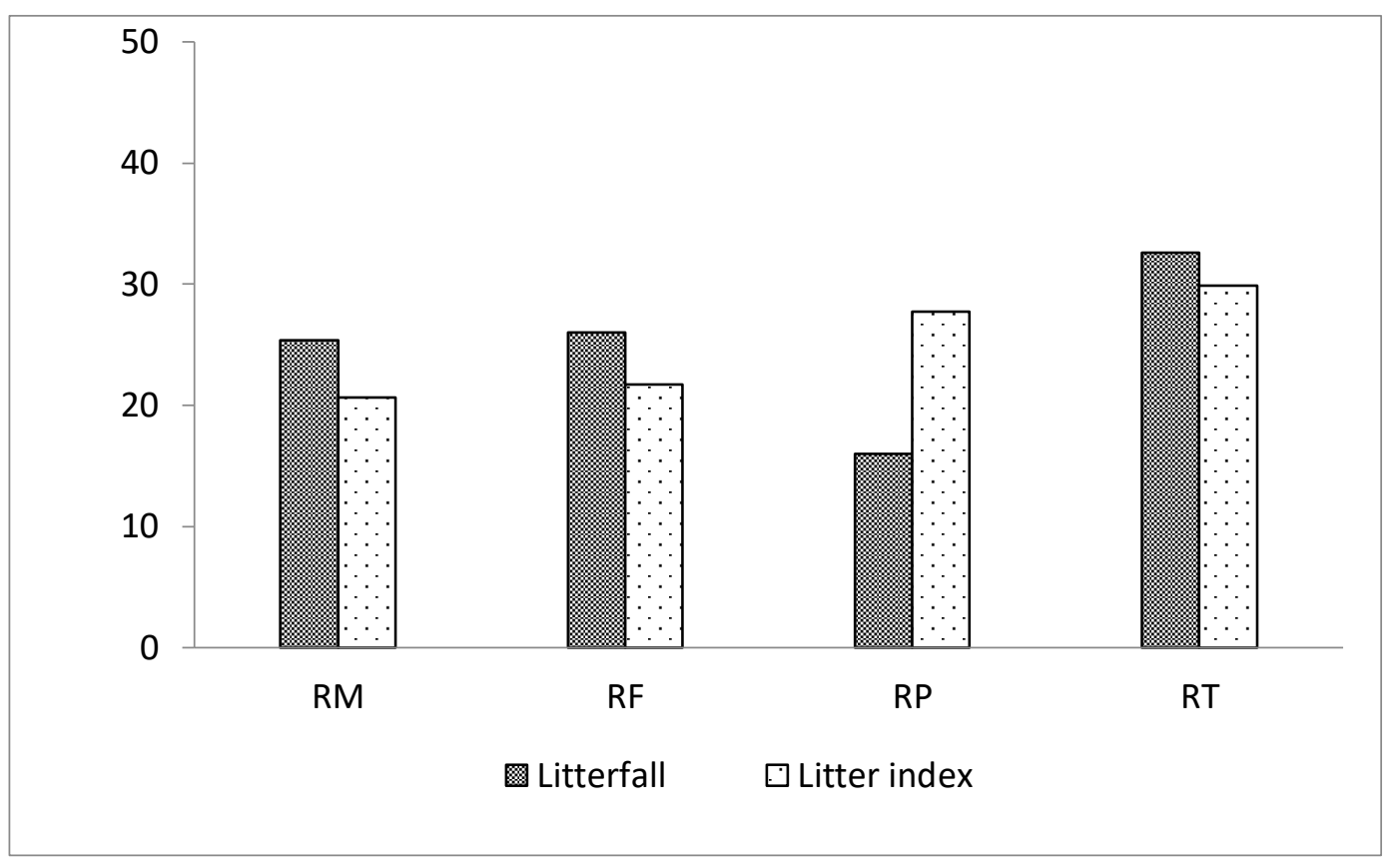

Figure 2. Percentage of litterfall and litter index in rubber monoculture and rubber-based agroforestry systems, rubber monoculture (RM), rubber with fruit (RF), rubber with pakliang (RP) and rubber with timber (RT).

\subsection{Soil macrofauna}

Macrofauna identified order-level classifications of Coleoptera, Hymenoptera, Isoptera, Isopoda, Diplura, Araneida, Chilopoda, Collembola, Stylommatophora and Earthworms at both rubber monoculture sites and rubber-based agroforestry plantations. These were not statistically different in the three intra-couple differences. Hymenoptera and Araneida were found in both systems. The macrofauna order communities were found in soil density at layers of $5-10 \mathrm{~cm}$ particularly in Pair III (RT and RMT). It was also noteworthy that earthworms were found in the topsoil, especially in rubber monoculture plantations, except in plots of RP (Pair II), which had a higher incidence of earthworms. Bruyn (1997) found that soil macrofauna, particularly earthworms, have been promoted as indicators of soil health. Earthworm function in soil processes is essential to understanding ecosystem function. Brown et al. (2001) reported that the diverse range of organisms and functions among macrofauna communities that perform in the soil combines to produce a diversity in biogenic soil structures that help regulate soil physical properties and processes, such as $\mathrm{C}$ and nutrient cycles. This further provides a whole host of ecosystem services that help increase heterogeneity in soils and improve soil ecosystem resilience and resistance to ecological disequilibria (e.g., pest outbreaks, degradation). Furthermore, several representatives of the soil fauna have also been proposed as bioindicators of soil health and sustainability. Many of the byproducts of organisms are used as food resources by other soil fauna. Also included are the soilfeeding (geophagous) bioturbators, important in opening channels within the soil and on its surface, affecting hydrological processes and gaseous exchanges, as well as modifying soil structure, aggregate formation, and even soil formation rates. Finally, among the beneficiaries also counted are the predatory organisms that act at the top of the soil food chain, feeding on other soil and surface-dwelling or active organisms, controlling their populations and often helping to counteract pest outbreaks (thus acting as bio-control agents). Therefore, this study indicated that soil health in rubber-based agroforestry plantations had higher trends when compared with rubber monoculture 
plantations.

\subsection{Decomposition of mesofauna}

Decomposition factors in rubber monoculture and rubber-based agroforestry plantations had no statistical difference in the three intra-couple differences. Rubber-based agroforestry plantations tended towards higher decompose rates than rubber monoculture plantations (Table 4). However, the litter decomposition scale of mesofauna were found in RT plots, which decomposed at higher rates than other plots. This is probably due to factors resulted from high macrofauna communities (Figure 3). Bradford et al. (2002) reported that plant litter decomposition is a key process in C and nutrient cycling. The critical role of soil-faunal community composition in decomposition has been demonstrated using different mesh size litterbags to control the exposure of litter to different faunal size classes. Relative effects of manipulated faunal community composition on litter mass loss and $\mathrm{C}$ : $\mathrm{N}$ ratio was equivalent for green and senesced litter. The presence of meso- and macrofauna increased litter decomposition rates overall, despite inhibiting decomposition by microfauna, bacteria, and fungi through indirect effects. Ke et al. (2005) found that farming systems influenced decomposition by affecting both element turnover and mesofauna. In the soil at integrated farming sites, mesofauna reduced cumulative $\mathrm{CO}_{2}$ production by $10 \%$ whereas in the soil from organic farming it increased $\mathrm{CO}_{2}$ production by $20 \%$. Villamor et al. (2014) reported that biodiversity in rubber agroforests indicate an eco-certification scheme opportunity by making the claim that such approaches help to reduce carbon emissions and species loss better than monoculture scenarios (monoculture rubber and oil palm). This study showed that mesofauna community dynamics implied that rubber-based agroforestry plantations have higher $\mathrm{C}$ and $\mathrm{N}$ turnover trends, which resulted in higher levels than in rubber monoculture plantations. However, a future study on the different management systems on soil mesofauna would be able to more accurately parse out these dynamics. 
Table 3. Average of macrofauna orders found in soil layer at 0-5 cm and $5-10 \mathrm{~cm}$ in rubber monoculture and rubber-based agroforestry systems.

\begin{tabular}{|c|c|c|c|c|c|c|c|c|c|c|c|c|c|c|c|c|c|c|}
\hline \multirow{3}{*}{ Macrofauna } & \multicolumn{6}{|c|}{ Pair I } & \multicolumn{6}{|c|}{ Pair II } & \multicolumn{6}{|c|}{ Pair III } \\
\hline & \multicolumn{3}{|c|}{$0-5 \mathrm{~cm}$} & \multicolumn{3}{|c|}{$5-10 \mathrm{~cm}$} & \multicolumn{3}{|c|}{$0-5 \mathrm{~cm}$} & \multicolumn{3}{|c|}{$5-10 \mathrm{~cm}$} & \multicolumn{3}{|c|}{$0-5 \mathrm{~cm}$} & \multicolumn{3}{|c|}{$5-10 \mathrm{~cm}$} \\
\hline & $\mathrm{RF}$ & MRF & T-test & $\mathrm{RF}$ & MRF & T-test & $\mathrm{RP}$ & MRP & T-test & $\mathrm{RP}$ & MRP & T-test & RT & MRT & T-test & RT & MRT & T-test \\
\hline Coleoptera & 0 & 0 & - & 0 & 0 & - & 0 & 0 & - & 0.67 & 0.57 & ns & 0.17 & 0.15 & ns & 0.67 & 0.77 & ns \\
\hline Hymenoptera & 2 & 2.14 & ns & 0.33 & 0.33 & ns & 0.33 & 0.3 & ns & 1 & 0.85 & ns & 3.33 & 3.19 & ns & 5.67 & 5.22 & ns \\
\hline Isoptera & 0 & 0 & - & 0 & 0 & - & 2.5 & 2.73 & ns & 0.33 & 0.38 & ns & 0.33 & 0.33 & ns & 0.5 & 0.43 & ns \\
\hline Isopoda & 1.17 & 1.15 & ns & 0.5 & 0.48 & ns & 0 & 0 & - & 1.33 & 1.48 & ns & 0 & 0 & - & 2.17 & 2.39 & ns \\
\hline Diplura & 0 & 0 & - & 0.33 & 0.3 & ns & 0.17 & 0.15 & ns & 1.67 & 1.62 & ns & 0 & 0 & - & 1.5 & 1.39 & ns \\
\hline Araneida & 0.33 & 0.3 & ns & 0.17 & 0.15 & ns & 0.33 & 0.3 & ns & 0.5 & 0.52 & ns & 0.67 & 0.63 & ns & 0.33 & 0.33 & ns \\
\hline Chilopoda & 0 & 0 & - & 0.33 & 0.33 & ns & 0.33 & 0.37 & ns & 0.33 & 0.38 & ns & 0 & 0 & - & 0.5 & 0.48 & ns \\
\hline Collembola & 0.17 & 0.15 & ns & 0.33 & 0.3 & ns & 0.33 & 0.37 & ns & 0 & 0 & - & 0 & 0 & - & 0.33 & 0.28 & ns \\
\hline Stylommatophora & 0 & 0 & - & 0 & 0 & - & 0.17 & 0.15 & ns & 0 & 0 & - & 0 & 0 & - & 0 & 0 & - \\
\hline Earthworm & 0.11 & 0 & ns & 7.11 & 10 & ns & 0 & 0 & - & 14.33 & 12.11 & ns & 0.22 & 0.22 & ns & 8.89 & 12.33 & ns \\
\hline
\end{tabular}

Note: $n s=$ not significant, $\mathrm{RF}=$ rubber with fruit, $\mathrm{RMF}=$ rubber monoculture compared with $\mathrm{RF}, \mathrm{RP}=$ rubber with pakliang, $\mathrm{RMP}=$ rubber monoculture compared with $\mathrm{RP}, \mathrm{RT}=$ rubber with timber and RMT =rubber monoculture compared with RT. 
Table 4. Comparison of litter decomposition in rubber monoculture and rubber-base agrotorestry systems.

\begin{tabular}{|c|c|c|c|c|c|c|c|c|c|}
\hline & \multicolumn{3}{|c|}{ Pair I } & \multicolumn{3}{|c|}{ Pair II } & \multicolumn{3}{|c|}{ Pair III } \\
\hline & $\mathrm{RF}$ & RMF & T-test & $\mathrm{RP}$ & RMP & T-test & RT & RMT & T-test \\
\hline Decomposition & 0.99 & 0.82 & $\mathrm{~ns}$ & 0.83 & 0.73 & ns & 0.86 & 0.78 & ns \\
\hline
\end{tabular}

Note: $n s=$ not significant, $R F=$ rubber with fruit, RMF=rubber monoculture compared with RF, RP =rubber with pakliang, $\mathrm{RMP}=$ rubber monoculture compared with $\mathrm{RP}, \mathrm{RT}=$ rubber with timber and $\mathrm{RMT}=$ rubber monoculture compared with RT.

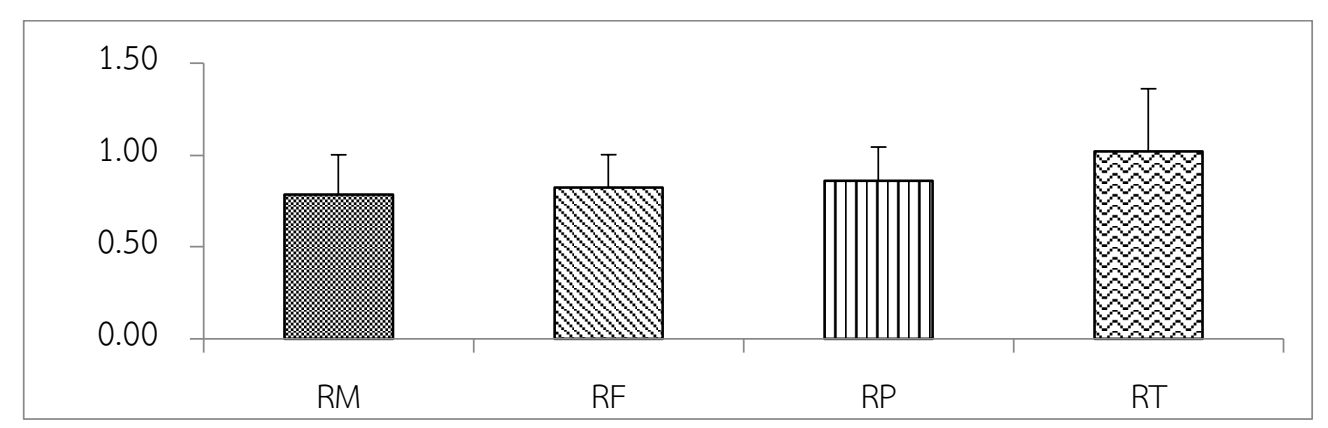

Figure 3. Litter decomposition scale of mesofauna fall in rubber monoculture and rubber-based agroforestry systems. Mean data calculated from a score of decomposition levels: $2=$ complete decomposition, 1 = incomplete decomposition, and $0=$ non decomposed between rubber monoculture (RM), rubber with fruit (RF), rubber with pakliang (RP) and rubber with timber (RT).

\subsection{Physical-chemical soil properties}

Three intra-couple differences were found by examining $\mathrm{pH}, \mathrm{EC}$, organic matter and nutrient contents, which were not statistically different in the two soil layers, except for calcium. Topsoil was more likely to have higher nutrient levels than subsoil, particularly in pair II (RP and RMP) and pair III (RT and MRT). Calcium, potassium, and magnesium in topsoil had a tendency to be high, especially in pair II (RP and RMP). The physical-chemical soil properties in intra-couples showed no differences due to the very similar areas. However, when compared between rubber monoculture with rubberbased agroforestry plantations, nutrient contents in the topsoil had higher values than the subsoil mainly evident from calcium content. RP and RT had soil nutrients in the topsoil higher than subsoil and also likely had higher nutrients than RF and RM. Calcium, potassium, and magnesium in topsoil were dominant among the intra-couples (Table 5). RP normally had less litterfall due to pakliang usage of young leaves for consumption like a vegeta ble, in which farmers needed to use more fertilizers for stimulation of the leaves during the juvenile phase. Nutrient content were found, probably a residual from fertilizer application. RT likely contained more nutrients due to the return levels from litterfall of rubber trees and timber trees. RF had fewer nutrient content due to the need for higher nutrients for fruit development and litter decomposition levels were lower. This study is consistent with Yang, et al. (2004), which reported that litterfall and litter decomposition acts as a source of essential nutrients. This includes $\mathrm{N}, \mathrm{P}$, and $\mathrm{K}$ that are returned to plants. There were also $\mathrm{Ca}$ and $\mathrm{Mg}$, depending on the species and the type of litterfall. Pausch et al. (2013) mentioned that land uses also affect the amount of organic carbon produced by degradation of soil microorganisms. Farmland areas had organic carbon rather than natural and semi-natural areas. However, agricultural land use had differences in organic carbon and nitrogen content, such as the oak plots which had higher organic carbon and nitrogen content than the maize plots. Therefore, it can be seen the activities that affect land use also results in varying amounts of organic matter thus changing local ecosystem dynamics. 
Table 5 Soil nutrients in topsoil $(0-5 \mathrm{~cm})$ and subsoil $(0-5 \mathrm{~cm})$ among rubber monoculture and rubber-based agroforestry systems.

\begin{tabular}{|c|c|c|c|c|c|c|c|c|c|c|c|c|c|c|c|c|c|c|}
\hline \multirow{3}{*}{ Soil analysis } & \multicolumn{6}{|c|}{ Pair I } & \multicolumn{6}{|c|}{ Pair II } & \multicolumn{6}{|c|}{ Pair III } \\
\hline & \multicolumn{3}{|c|}{ topsoil $(0-5 \mathrm{~cm})$} & \multicolumn{3}{|c|}{ sub-soil $(5-10 \mathrm{~cm})$} & \multicolumn{3}{|c|}{ topsoil $(0-5 \mathrm{~cm})$} & \multicolumn{3}{|c|}{ subsoil $(5-10 \mathrm{~cm})$} & \multicolumn{3}{|c|}{ topsoil $(0-5 \mathrm{~cm})$} & \multicolumn{3}{|c|}{ subsoil $(5-10 \mathrm{~cm})$} \\
\hline & $\mathrm{RF}$ & RMF & T-test & $\mathrm{RF}$ & RMF & T-test & $\mathrm{RP}$ & RMP & T-test & $\mathrm{RP}$ & RMP & T-test & RT & MRT & T-test & RT & RMT & T-test \\
\hline $\mathrm{pH}$ & 5.07 & 5.07 & ns & 4.8 & 4.89 & ns & 5.01 & 4.92 & ns & 4.66 & 4.62 & ns & 5.14 & 4.78 & ns & 4.76 & 4.7 & ns \\
\hline $\mathrm{EC}(\mathrm{dS} / \mathrm{m})$ & 0.03 & 0.03 & ns & 0.02 & 0.02 & ns & 0.03 & 0.02 & ns & 0.03 & 0.02 & ns & 0.02 & 0.03 & ns & 0.02 & 0.03 & ns \\
\hline Organic matter (\%) & 1.86 & 1.83 & ns & 1.5 & 1.39 & ns & 2.10 & 1.67 & ns & 1.89 & 1.58 & ns & 1.53 & 1.69 & ns & 1.26 & 2.01 & ns \\
\hline Phosphorus (mg/kg) & 5.01 & 3.76 & ns & 3.96 & 1.98 & ns & 5.81 & 2.52 & ns & 3.91 & 2.76 & ns & 3.7 & 4.18 & ns & 2.01 & 2.56 & ns \\
\hline Potassium (mg/kg) & 56.8 & 72.86 & ns & 44.69 & 39.32 & ns & 63.44 & 34.03 & ns & 46.41 & 31.92 & ns & 58.89 & 54.96 & ns & 40.76 & 39.37 & ns \\
\hline Calcium (mg/kg) & 60.68 & 65.43 & ns & 18.75 & 22.46 & ns & $128.24 a$ & $72.11 b$ & $*$ & 51.55 & 62.01 & ns & $120.38 a$ & $58.35 b$ & $*$ & $57.47 a$ & $30 b$ & $*$ \\
\hline Magnesium (mg/kg) & 21.13 & 20.54 & ns & 7.52 & 7.19 & ns & 24.76 & 17.33 & ns & 13.09 & 13.01 & ns & 29.55 & 15.52 & ns & 15.21 & 5.99 & ns \\
\hline
\end{tabular}

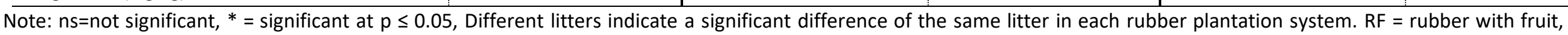

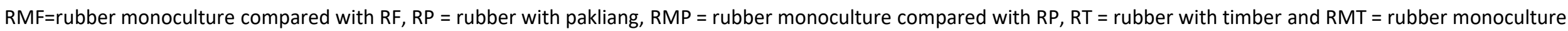
compared with RT. 


\section{Conclusion}

Three intra-couple differences were examined in this study and did not yield statistically significant differences in litterfall, litter decomposition, soil macrofauna, and nutrient contents among rubber monoculture and rubber-based agroforestry plantations. However, rubber-based agroforestry plantations, particularly RT sites, had litterfall levels higher than other rubber plantations and had the tendency for higher plant part decomposition. Macrofauna was also found at higher density levels in rubber-based agroforestry plantations. Nutrient content was also higher in the topsoil at these sites, and calcium dominated the intra-couples. This information provides evidence that therefore supports rubber farmer decisions to grow rubber-based agroforestry due to the carbon returns from litterfall in rubber-based agroforestry plantations. This will help regulate physical properties and processes of the soil, and further support $C$ and nutrient cycles that benefit against low external input fertilizer management. Therefore, government agencies should support these practices, and recommend that other farmers in the region also consider the broader soil dynamics. This study has shown that these more fine-grained ecosystem dynamics can also help to make a difference in changing agrarian practices.

\section{Acknowledgments}

Thanks to the Hevea Research Platform in Partnership and LUSES, An International Joint Laboratory on the Impacts of Rapid Land Use Change on Soil Ecosystem Services who supported this research financially. Special thanks to the rubber farmers that allowed us on their rubber plantations and took the time to discuss with us for this study.

\section{References}

Austin A. T., Luc V., Adelia G. A. \& Luis I. P. (2014). There's no place like home? An exploration of the mechanisms behind plant litter-decomposer affinity in terrestrial ecosystems. New Phytologist. 204: 307-314.

Bradford, M.A., George M. T., Till E., Jones T. H. \& John E. N. (2002). Microbiota, fauna, and mesh size interactions in litter decomposition. OIKOS. 99 (2): 317-323.

Brown, G.G., Amarildo P., Norton P.B., Adriana M.A. \& Maria E.F.C. (2001). Diversity and functional role of soil macrofauna communities in Brazilian no tillage agroecosystems: A preliminary analysis. Paper based on an oral presentation at the "International Symposium on Managing Biodiversity in Agricultural Ecosystems" Montreal, Canada, 8-10 November, 2001.

Bruyn, L. A. L. (1997). The status of soil macrofauna as indicators of soil health to monitor the sustainability of Australian agricultural soils. Ecological Economics. 23 (2): 167-178.

Chen, C., W. L. Xiaojin \& J. J. Wu. (2017). Effects of rubber-based agroforestry systems on soil aggregation and associated soil organic carbon: Implications for land use. Geoderma. 299:1324.

Cizungua, L., Jeroen S., Dries H., Jean W., Daniel M., Oswald V. C. \& Pascal B. (2014). Litterfall and leaf litter decomposition in a Central African tropical mountain forest and eucalyptus plantation. Forest Ecology and Management. 326: 109-116.

Kaspari, M., Milton N. G., Kyle E. H., Mirna S., Joseph S. W. \& Joseph B. Y. (2008). Multiple nutrients limit litterfall and decomposition in a tropical forest. Ecology Letters. 11 (1): 35-43.

Ke, X. Karin W. \& Juliane F. (2005). Effects of soil mesofauna and farming management on decomposition of clover litter: a microcosm experiment. Soil Biology and Biochemistry. 37 (4): 731-738.

ORRAF (Office of Rubber Replanting Aid Fund). (2006). A study of problems and occupational development needs of rubber plantation farmers. Research and Planning Office of the Rubber Aid Fund. Ministry of Agriculture and Cooperatives. (In Thai).

Pausch, J., Zhu B., Kuzyakov Y. \& Cheng W. (2013). Plant inter-species effects on rhizosphere priming 
of soil organic matter decomposition. Soil Biology \& Biochemistry. 57: 91-93.

Sarah, A. (2016). There's no place like home an exploration of the mechanisms behind plant litterdecomposer affinity interrestrial ecosystems. https://besplantsoileco.wordpress.com accessed on 28 September 2016.

Stroesser, L., Penot E., Michel I., Tongkaemkaew U. \& Chambon B. (2018). Income diversification for rubber farmers through agroforestry practices: How to withstand rubber price volatility in Phatthalung Province, Thailand. Revue internationale des études du développement. 235(3): 115-143.

Villamor, G.B., Quang B. L., Utkur D., Meinevan N. \& Paul L.G.V. (2014). Biodiversity in rubber agroforests, carbon emissions, and rural livelihoods: An agent-based model of land-use dynamics in lowland Sumatra. Environmental Modelling \& Software. 61: 151-165.

Wang, Q., S. Wang \& Y. Huang. (2008). Comparisons of litterfall, litter decomposition and nutrient return in a monoculture Cunninghamia lanceolata and a mixed stand in southern China. Forest Ecology and Management. 255: 1210-1218.

Yang, Y. S., J. F. Guo, G. S. Chen, J. S. Xie, L. P. Cail \& P. Lin. (2004). Litterfall, nutrient return, and leaflitter decomposition in four plantations compared with a natural forest in subtropical China. Annals of Forest Science. 61(5): 465-476.

Pabsta, H., Kuhnelb A., Kuzyakova Y. (2013). Effect of land-use and elevation on microbial biomass and water extractable carbon in soils of Mt. Kilimanjaro ecosystems. Applied Soil Ecology. 67: 10-9. 